\title{
DOENÇA CÍSTICA MEDULAR DO RIM: RELATO DE UM CASO DIAGNOSTICADO POR ULTRA-SONOGRAFIA E TOMOGRAFIA COMPUTADORIZADA*
}

\author{
Tarcísio Nunes Carvalho ${ }^{1}$, Cyrillo Rodrigues de Araújo Jr. ${ }^{1}$, Sérgio Roberto Fraguas Filho ${ }^{1}$, \\ Marlos Augusto Bittencourt Costa ${ }^{1}$, Flávia Aparecida de Souza Ribeiro ${ }^{2}$, Kim-Ir-Sen Santos \\ Teixeira $^{3}$
}

Resumo Doença cística medular, nefronofitíase juvenil familiar ou complexo de doença cística medular referem-se a um grupo de doenças similares cuja lesão básica é uma progressiva atrofia tubular renal com esclerose glomerular e formação cística medular. É importante causa de insuficiência renal em pacientes adolescentes. Estudos de imagem têm papel principal no diagnóstico desta enfermidade, com cistos caracteristicamente individualizados na medula renal e junção córtico-medular e tamanho renal normal ou reduzido. Neste artigo demonstramos os achados de imagem da doença cística medular renal em uma adolescente com quadro clínico característico, por meio de ultra-sonografia e tomografia computadorizada.

Unitermos: Nefronofitíase juvenil familiar - complexo de doença cística medular; Ultra-sonografia; Tomografia computadorizada.

Abstract Medullary cystic disease of the kidney: report of a case diagnosed by ultrasonography and computed to-
mography examinations.
The terms medullary cystic disease, juvenile nephronophthisis or medullary cystic disease complex refer to
a group of similar diseases in which the basic pathological abnormality is progressive renal tubular atrophy
with secondary glomerular sclerosis and medullary cystic formation. Medullary cystic disease is an important
cause of renal failure in adolescent patients. Imaging methods play a primary role in the diagnosis of these
diseases. Cysts are characteristically seen in the renal medulla and corticomedullary junction whereas kidneys
may be of normal to small size. In this article we present the ultrasonography and computed tomography
findings of a female adolescent patient with characteristic clinical picture of medullary cystic disease.
Key words: Familial juvenile nephronophthisis - medullary cystic disease complex; Ultrasonography; Com-
puted tomography.

\section{INTRODUÇÃO}

A doença cística medular é uma causa progressiva de insuficiência renal em adolescentes e adultos jovens, compreendendo duas formas principais.

A variedade com início juvenil, conhecida como nefronofitíase juvenil, tem herança autossômica recessiva. A segunda forma, referida como doença cística medular, desenvolve-se em adultos jovens, sendo transmitida por um gene autossômico

* Trabalho realizado no Serviço de Diagnóstico por Imagem do Hospital das Clínicas da Faculdade de Medicina da Universidade Federal de Goiás (HC-FMUFG), Goiânia, GO.

1. Médicos Residentes do Departamento de Diagnóstico por Imagem do HC-FMUFG.

2. Médica Cooperada do Serviço de Diagnóstico por Imagem do HC-FMUFG.

3. Professor Adjunto, Chefe do Serviço de Diagnóstico por Imagem do HC-FMUFG.

Endereço para correspondência: Dr. Tarcísio Nunes Carvalho. Rua C-167, ㄲo 130, Setor Nova Suíça. Goiânia, G0, 74255-100. E-mail: Tarcisionunes@hotmail.com.br

Recebido para publicação em 20/3/2003. Aceito, após revisão, em 9/5/2003. dominante. Estas formas são geralmente entendidas como expressões diferentes de uma única doença e consideradas, por muitos autores, como complexo de doença cística medular ${ }^{(\mathbf{1})}$. Casos esporádicos também podem ocorrer.

Os pacientes apresentam um início insidioso, com hipostenúria (poliúria, polidipsia e enurese), anemia, retardo de crescimento (em crianças) e progressiva insuficiência renal $^{(2)}$.

A ultra-sonografia (US) e a tomografia computadorizada (TC) são métodos importantes na diferenciação com as outras doenças císticas renais ${ }^{(\mathbf{3})}$.

\section{RELATO DO CASO}

Uma adolescente de 13 anos de idade foi encaminhada ao nosso Serviço com quadro clínico de hipostenúria importante, referindo poliúria, polidipsia e enurese noturna. Estes sintomas iniciaram há cer- ca de um ano. A paciente negava infecção urinária prévia e casos semelhantes na família.

Ao exame clínico observava-se acentuado déficit pôndero-estatural, palidez cutâneo-mucosa e "bexigoma" palpável.

A avaliação laboratorial mostrou anemia moderada, com hemoglobina de 10,0 g/dl, e azotemia, com uréia de $112 \mathrm{mg} / \mathrm{dl}$ e creatinina de $1,9 \mathrm{mg} / \mathrm{dl}$. O exame da urina foi negativo para proteínas e hemácias. A urocultura foi negativa.

O primeiro exame de imagem realizado foi a US, que evidenciou achados característicos da doença cística medular. Havia, porém, acometimento assimétrico com redução do tamanho renal apenas à esquerda, não-usual nesta enfermidade. Os achados, em ambos os rins, foram aumento da ecogenicidade parenquimatosa, com redução da diferenciação córtico-medular, e múltiplos pequenos cistos medulares e na junção córtico-medular, com diâmetro 
máximo de $10 \mathrm{~mm}$ (Figura 1). A bexiga apresentava capacidade aumentada. Não havia alterações evidentes em outros órgãos abdominais.

Foi realizada TC com contraste endovenoso, em cortes axiais de $5 \mathrm{~mm}$ e deslo-



Figura1. Ultra-sonografia mostrando aumento da ecogenicidade do parênquima renal, com redução da diferenciação córtico-medular e múltiplos cistos medulares. camento de $5 \mathrm{~mm}$, que confirmou a presença dos múltiplos cistos medulares e na junção córtico-medular, com redução do tamanho apenas do rim esquerdo (Figura 2).

\section{DISCUSSÃO}

Um grupo de doença cística renal tem sido resumido com o termo "complexo nefronofitíase-doença cística medular renal", desde que compartilhem os seguintes fatores em comum: sintomas clínicos de poliúria, polidipsia, anemia, déficit pôndero-estatural e insuficiência renal crônica; patologia macroscópica com cistos córtico-medulares; e histologia renal demonstrando lesão da membrana basal tubular, infiltração de células redondas com marcante fibrose intersticial, e atrofia e ectasia tubular ${ }^{(4)}$.

Nefronofitíase foi descrita primeiramente por Fanconi et al. O termo comple- xo nefronofitíase-cisto medular renal foi proposto por Gardner ${ }^{(\mathbf{5})}$ para descrever um grupo de doenças com fatores clínicos e patológicos semelhantes mas herança genética diferente. Estas incluem a nefronofitíase (autossômica recessiva), a síndrome de Sênior Loken (nefronofitíase associada a degeneração retiniana, autossômica recessiva), a doença cística medular com início no adulto (autossômica dominante) e casos esporádicos ${ }^{(\mathbf{6})}$.

Casos suspeitos de doença cística medular deveriam ser inicialmente avaliados com US. Em contexto clínico compatível, os achados de pequenos cistos medulares ou córtiço-medulares e rins de tamanho normal ou reduzido com aumento da ecogenicidade devem ser considerados patognomônicos de doença cística medular ${ }^{(2)}$.

Os cistos medulares, apesar de característicos desta condição, são raramente evidenciados no espécime de biópsia renal
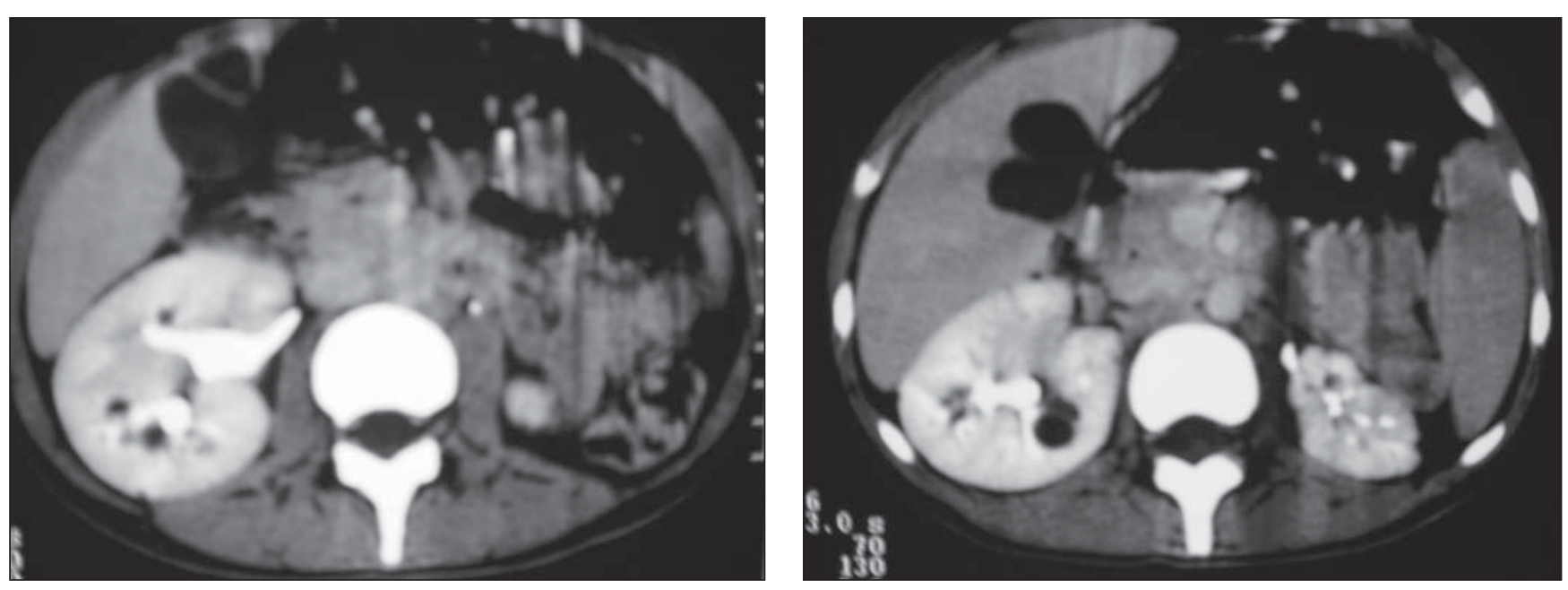

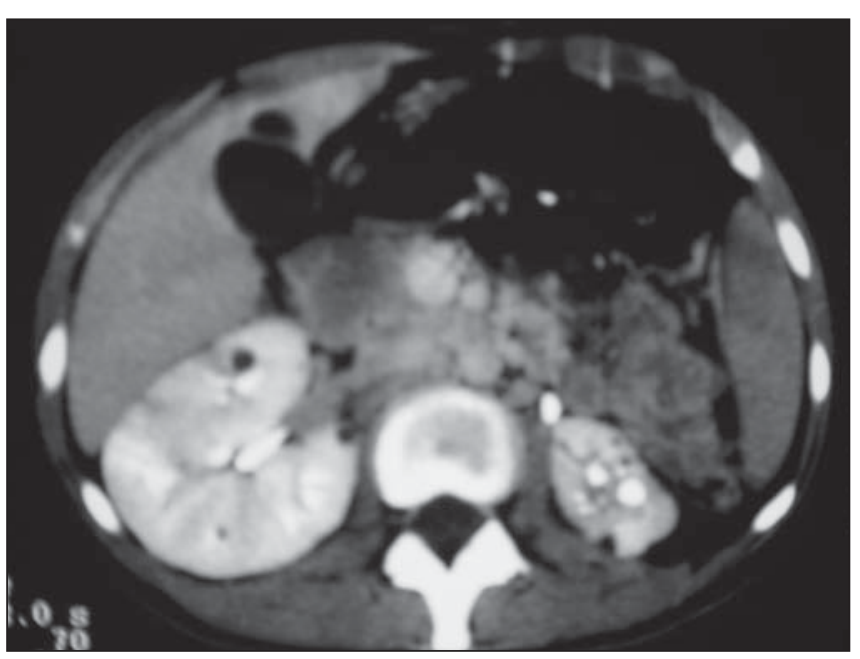

Figura 2. Tomografia computadorizada pós-contraste evidenciando múltiplos cistos medulares e na junção córtico-medular, com diâmetro máximo de 10 mm. Rim esquerdo reduzido de tamanho. 
percutânea. A urografia excretora geralmente não é útil no diagnóstico. A US é o método de escolha no diagnóstico desta afecção, porém depende do examinador, e, além disso, os pequenos cistos medulares podem não ser individualizados ${ }^{(7,8)}$.

A TC com cortes finos e contraste endovenoso é um ótimo método para detectar os cistos medulares ${ }^{(\mathbf{6})}$.

A ressonância magnética pode ser indicada como um exame de segunda linha quando a US é inconclusiva, sendo que há contra-indicação ao uso do contraste iodado endovenoso ${ }^{(\mathbf{1})}$.

Quando os cistos medulares são identificados por US ou TC, a diferenciação com outras enfermidades renais é facilitada. Quando os cistos são muito pequenos e, contudo, não-detectados (também deno- minada doença cística medular acística), o diagnóstico por imagem é dificultado. Fatores clínicos, biópsia renal e história familiar podem auxiliar nestes casos ${ }^{(2)}$.

Num contexto clínico compatível, associado aos achados de imagem característicos na US e na TC, este caso foi diagnosticado como doença cística medular. Um achado incomum desta enfermidade foi evidenciado neste caso, visto apresentar redução no tamanho de apenas um rim. $\mathrm{O}$ aumento da capacidade vesical foi atribuído à excreção constante de urina com baixa densidade (hipostenúria).

\section{REFERÊNCIAS}

1. Wise SW, Hartman DS, Hardesty LA, Mosher TJ. Renal medullary cystic disease: assessment by MRI. Abdom Imaging 1998;23:649-51.

2. Resnick JS, Hartman DS. Medullary cystic disease of the kidney. In: Pollack HM, ed. Clinical urography. Philadelphia, PA: Saunders, 1990:1178-84.

3. Levine E, Hartman DS, Meilstrup JW, Van Slyke MA, Edgar KA, Barth JC. Current concepts and controversies in imaging of renal cystic diseases. Urol Clin North Am 1997;24:523-43.

4. Hildebrandt F, Omram H. New insights: nephronophthisis-medullary cystic kidney disease. Pediatr Nephrol 2001;16:168-76.

5. Gardner KD Jr. Juvenile nephronophthisis and renal medullary cystic disease. In: Gardner KD Jr, ed. Cystic diseases of the kidney. New York: John Wiley, 1976:173.

6. Elzouki AY, al-Suhaibani H, Mirza K, al-Sowailem AM. Thin-section computed tomography scans detect medullary cysts in patients believed to have juvenile nephronophthisis. Am J Kidney Dis 1996; 27:216-9.

7. Blowey DL, Querfeld U, Geary D, Warady BA, Alon U. Ultrasound findings in juveline nephronophthisis. Pediatr Nephrol 1996;10:22-4.

8. Chuang YF, Tsai TC. Sonographic findings in familial juvenile nephronophthisis-medullary cystic disease complex. J Clin Ultrasound 1998;26:203-6. 